\title{
Failure analysis of recurrent cases of fatigue fracture in flash butt welded rails
}

\author{
L.B. Godefroid *, G.L. Faria, L.C. Cândido, T.G. Viana \\ Universidade Federal de Ouro Preto, Ouro Preto, Minas Gerais, Brazil
}

\section{A R T I C L E I N F O}

\section{Article history:}

Received 13 December 2014

Received in revised form 26 April 2015

Accepted 5 May 2015

Available online 8 June 2015

\section{Keywords:}

Rails

Flash butt welding

Fatigue cracking

\begin{abstract}
A B S T R A C T
Medium carbon steel rails are commonly jointed by flash butt welding procedures. To ensure an adequate service life for the structural component, commonly subjected to fatigue loading, a rigorous quality control should be performed, both in welding parameters and in the surface quality of the welded joint. This work investigated the causes of recurrent failures in railroads, with cracking always initiated in the rail in the region of the welded joint. Two case studies are presented. Aiming to execute the failure analysis, all standard procedures were applied, with a careful assessment of the material characteristics and the fractured surface. It was concluded that, for both cases, fatigue cracks initiated near the weld bead and spread in a brittle mode, leading to premature fracture of the material. An in-depth analysis of the rails showed that the surface finishing of the weld bead was not appropriate, generating undesirable stress concentration. Some undesirable microstructural characteristics were also found in the weld region. A recommendation to control welding parameters and to change the procedure of surface finishing of welded joints was held, aiming to decrease the number of accidents on the railroads.
\end{abstract}

(c) 2015 Elsevier Ltd. All rights reserved.

\section{Introduction}

In continental countries like Brazil, logistics questions related mainly to the transport of high volumes for long distances must be accurately treated. The railroad is one of the most efficient and economical transport ways to attend this demand [1]. The Brazilian railroad network is used by many companies (for example, VALE, one of the largest iron ore companies in the world) for transportation of minerals, agricultural products and passengers. The railroad sector adopts the American AREMA Manual for Railway Engineering [2] for design, manufacture, joining and maintenance of steel rails.

The railway transport is an efficient transport way mainly if railroads have their integrity preserved during their service lives. Rails catastrophic failures during a train passage, may cause the train derailment, resulting in accidents with human lives and material goods losses [3-8]. Aiming to increase the railroad service lifetimes, nowadays the manufacture of rails use modern steels with high mechanical strength and wear resistance. The majority of rail steels has an eutectoid composition with a pearlitic microstructure. The prior austenitic grain size, the pearlite colony size and the interlamellar spacing are factors that need to be controlled [9]. In addition, the proper choice of phases and constituents for steel, as the bainitic structure, can provide high values for tensile and fatigue strengths, and a good performance in service [10]. Moreover, due to the need to increase train capacity, size and speed, specific settings for the construction of railways have been employed. One example is the use of long welded rails in railway construction also continuously welded [8].

\footnotetext{
* Corresponding author. Tel.: +55 (31)35591106.

URL: leonardo@demet.em.ufop.br (L.B. Godefroid).
} 
Structural deterioration phenomena, which typically cause failure of modern rails, commonly involve stress and strain control fatigue and are related with wagon wheels and axles, and mechanical interactions with rails. Moreover, welded joints are microstructural discontinuities in railroads continuously welded and represent susceptive points for fatigue cracks nucleation and growth [7,8,11-13].

Nowadays, two welding processes are often used: flash butt welding and thermite welding. Flash butt welding is used to weld short rail sections aiming to obtain longer sections (400 m). This welding procedure is often done in a welding plant. The longer rail sections are then transported and welded one to the other in the track by thermite welding procedures.

The flash butt welding is a resistance welding method, often performed in stationary plants, which consists of electrical heating and hydraulic forging of the rail ends. On the other hand, the thermite welding method is a casting method and it is the most common method used in the track to make sections together. However, according to technical literature, both types of welding methods introduce a similar residual stress field in the foot, the web and the head of the rail. Many authors, using experimental and computational data, describe the welded rail web as the highest tensile residual stress area after fast cooling. According to them the residual stress distribution is very important to understand the rail fracture mechanism [14-18]. Another problem is that these rails are mainly constituted of pearlite and during the welding procedure the microstructural changes that happens in the heat-affected zone (HAZ) may degrades the mechanical welded joint properties. According to preview studies, the cementite is commonly globulized in this area and the yield and tensile strength locally decrease. In the welded zone, it is possible to occur austenite grain growth and carbide precipitation in their boundaries. These precipitations may decrease especially the steel fracture toughness [13-18].

In this context, this research investigated, from several recurrent cases with similar characteristics, the cause of two failures in flash butt welded joints of high strength rails used at Brazilian railroads, which were failed and caused serious accidents. These failures were considered arising from mechanical fatigue in rails, due to the nature of the stresses on the rails and observed characteristics in the analysis. The loads acting on the rails (about $200 \mathrm{kN}$ ) induce a stress state below the tensile yield stress of steels used in rails, and no overload was considered in these analyses. The failures in welded joints were analyzed and the main results were related, aiming to understand the causes and suggest improvements to the rail welding procedure.

\section{Materials and methods}

Standard procedures for failure analysis were applied in this work aiming to investigate two failure cases in flash butt welded joints. The fractured joints were preserved, sampled and submitted to several characterization methods.

The executed failure analysis involved the following principal stages: investigation about material's fabrication and use history, sampling procedures including the preservation (cleaning) of the fractured surface, macro and microfractographic analysis, chemical analysis, metallographic analysis and mechanical tests (tensile and hardness tests) for both samples.

\section{Results and discussion}

\subsection{Case 1}

\subsubsection{Macrofractographic analysis}

Fig. 1 presents the inferior part of the fracture surface of the rail, which was used in the macrofractographic analysis. It is possible to observe the fracture aspects at the head and at the web of rail. The rail web presents a region that reflects more intensely the light (flat and brightening). Fig. 1 also shows that this flat region is localized at the internal side of the railroad, where train wheels exert higher fatigue efforts over the structure. It is important to observe in this Figure the bad quality of the superficial

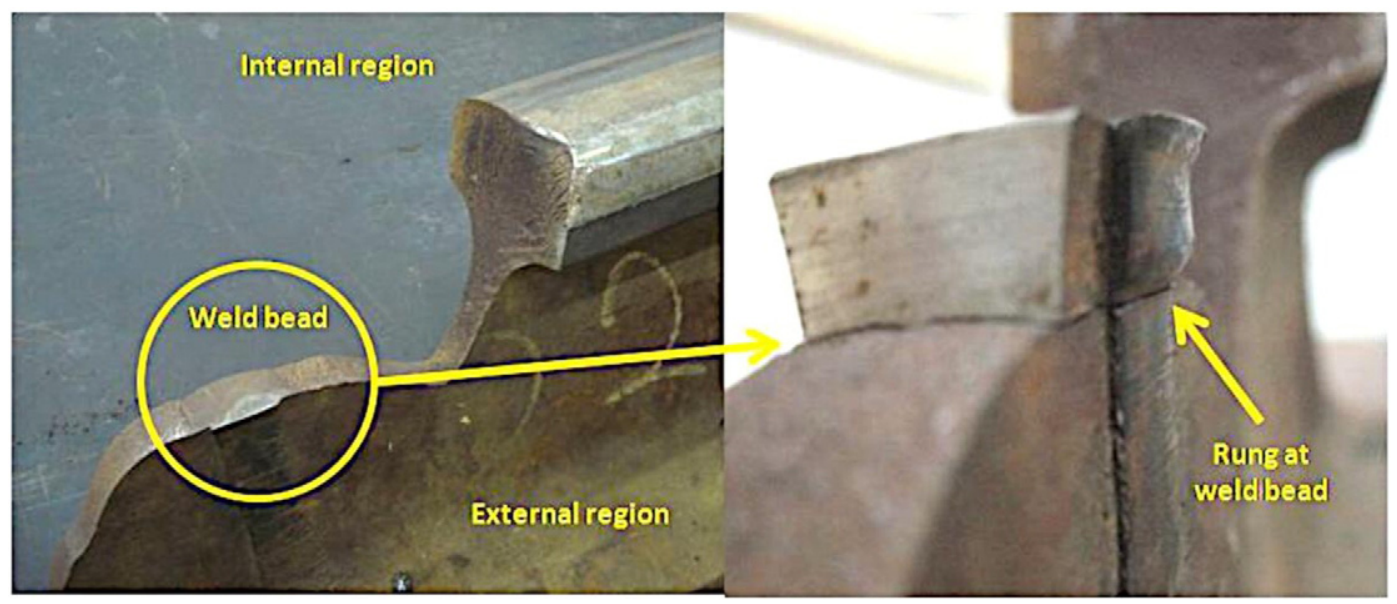

Fig. 1. Rail fracture surface, highlighting a rung at the welded bead. 
finishing. The problem is not lack of atomic union between the pieces during the welding or a geometrical misalignment of the rails in the welded junction, but the lack of adequate finishing after welding.

Fig. 2(a) presents a detail in the welded region. It is possible to observe three flat surfaces that reflect light more intensely. One of these flat surfaces, the biggest and central, highlights, because it has a curvature radius of almost one third of web rail thickness $(6 \mathrm{~mm})$. This area characterizes crack nucleation and stable crack growth. Chevron marks are observed at right and left side of the welded joint. This is an evidence of crack instable growth (brittle fracture, later confirmed in the microfractographic analysis) toward the head and the foot of the rail (residual stress regions), leading to the final collapse of the rail.

It is important to note that crack nucleation areas are localized at stress concentration regions: welded joint, sharp edges and grinding striations associated to the burr presences due to the welding procedure. These evidences, associated with a cyclic loading (below the material yield strength), which occurs in a normal operation routine of a railroad, lead to a final diagnosis of fatigue failure.

Fig. 2(b) presents details of unstable crack growth regions (head, web and foot). In these areas is possible to see chevron marks, indicating that these parts were fractured by a brittle mechanism. The brittle behavior was confirmed later in the microfractographic analysis. It is supposed that fatigue crack grew until get a specific curvature radius (one third of rail web), considered the critical size, and promoting a stress intensity factor correspondent to the material fracture toughness, causing a catastrophic failure at the welded joint.

\subsubsection{Chemical analysis}

The fractured rail was submitted to a chemical analysis by the optical emission spectrometry technique. The studied material is a hypereutectoid microalloyed steel. Carbon, vanadium and chrome contents are, respectively, 0.854\%, 0.095\% and 0.438\%. This steel presented $0.781 \%, 0.846 \%$ and $0.014 \%$ of $\mathrm{Si}$, Mn and P respectively. The expected microstructure for this steel is mainly constituted by pearlite.

The chemical composition of the steel is in accordance with AREMA Manual [2]. This standard recommends the minimum carbon content for this application as $0.74 \%$ and $0.72 \%$ for standard and low alloy rails, respectively. The Si, Mn, and P also meet the specification.

\subsubsection{Metallographic analysis}

As the crack nucleation occurred at the web of the rail, a selected and prepared surface for metallographic analysis was sampled in this area. Fig. 3 presents the prepared and etched (Nital 2\%) surface. It is possible to see the base metal (BM), the heataffected zone (HAZ) and the weld bead (WB). A central line (CL), revealed by its white contrast is also observed, and characterizes the method of union of rails by flash butt welding. Using this etched sample, it was possible to measure the distance between the two HAZs (35 mm). Samples were observed in an optical microscope (OM).

Fig. 4 presents micrographs of BM regions etched with Nital $2 \%$. As expected, the steel structure is constituted of pearlite. Coarse pearlite reflects more the incident light and the constituent is revealed more brilliant. Fine pearlite (major fraction) has darker colors, because its colonies reflect less light.

Fig. 5 presents micrographs of HAZ regions. These figures show the pearlite fragmentation (iron and carbon diffusion implied in the cementite lamellae partial disintegration) due to high heat input during welding process in this area.

Fig. 6 shows micrographs of WB regions. In this area it was possible to observe that pearlite colonies have higher sizes, indicating higher preexisting austenite grain sizes. In Fig. 7 it is possible to see the central line. In this line, the microstructure is constituted of pearlite and pro-eutectoid ferrite. Ferrite grains are localized at pearlite colonies boundaries, indicating local decarburization.

\subsubsection{Mechanical tests}

The used sample in the microstructural characterization was submitted to Brinell hardness tests (ASTM E10-08, force $=$ $187.5 \mathrm{kgf}$, diameter $=2.5 \mathrm{~mm}$ ). Measures were done in BM, HAZ, and WB regions and CL. Fig. 8 presents the Brinell hardness profile measured in the failed welded joint. As expected, obtained values in BM and WB were similar, because both structures

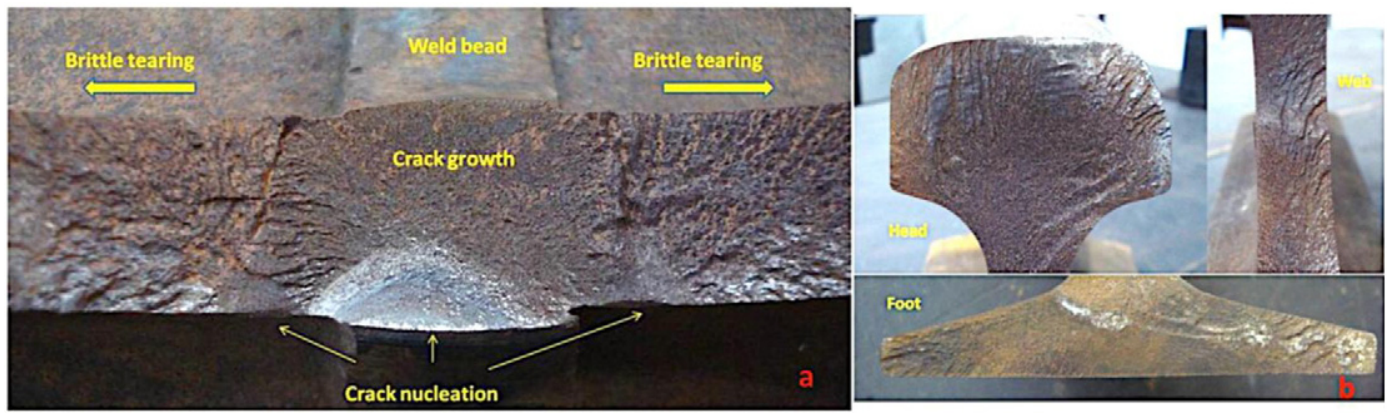

Fig. 2. (a) Detail of crack nucleation and stable growth regions (intense light reflection - flat surface). Brittle tearing areas (chevron marks); (b) Head, web and foot presenting brittle fracture surfaces. The rail web thickness is $18 \mathrm{~mm}$; fatigue crack depth is 6 mm; fatigue crack width is 16 mm. 


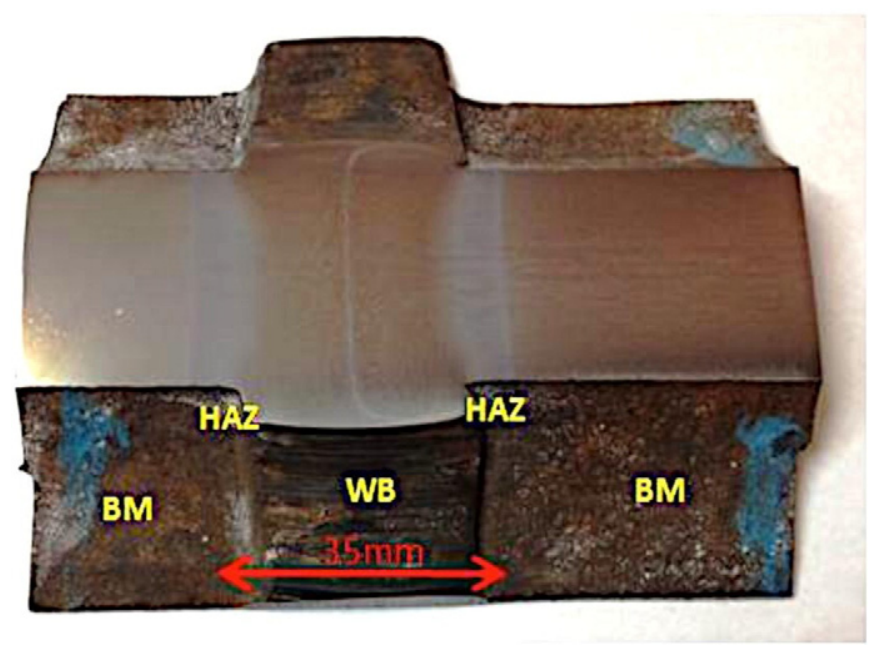

Fig. 3. Welded joint prepared for metallographic procedures. $\mathrm{BM}=$ base metal; $\mathrm{HAZ}=$ heat-affected zone; $\mathrm{WB}=$ weld bead; $\mathrm{CL}=\mathrm{central}$ line.

are pearlitic with small differences between colony sizes and interlamellar spacing. In CL, hardness values decrease slightly. This result may be explained due to pro-eutectoid ferrite presence in this area. In HAZ, hardness values presented a high decrease, justified by pearlite fragmentation verified in this region.

Tensile test specimens (ASTM E8 M-09; gage length $=30 \mathrm{~mm}$, diameter $=6 \mathrm{~mm}$ ) were sampled from the head of the rail in two different positions: a set of specimens was sampled out from the welded bead (far from welded joint, in the base metal region - BM); other set was sampled in the welded joint (weld bead region - WB, welded bead in the middle of specimen). Table 1 presents the main mechanical properties of the studied steel obtained in the tensile test for both conditions. It is possible to verify that yield $\left(\sigma_{\mathrm{ys}}\right)$ and tensile strength $\left(\sigma_{\mathrm{ts}}\right)$ of the specimens sampled in the WB region is lower than the measured for specimens sampled in the BM region, far from welded joint. Although the total strain (TS) for both configurations is similar, the area reduction (AR) is higher for the specimen sampled in the WB region.

Specimens sampled with the WB region presented highest AR and a fracture always out from the weld bead. Aiming to characterize these regions and to understand recurrent fractures at the same place, welded samples were etched with Nital $2 \%$. It was possible to observe that fracture systematically occurred at the HAZ region (softening region due to the formation of cementite globules).

\subsubsection{Microfractographic analysis}

The microfractographic analysis was performed in a scanning electron microscope (SEM). Fig. 9 was obtained using the same region as shown in Fig. 2(a). In Fig. 9(a) it is possible to confirm the phenomenon of fatigue as the main cause of crack nucleation and stable growth. This figure shows a flat fracture surface without plastic deformation and with beach marks, all typical of fatigue. Fig. 9(b) presents the transition area of stable to instable crack growth. In the part corresponding to the fatigue process it is still possible to see some beach marks. Finally, Fig. 9(c) reveals cleavage facets and river marks, indicating a final brittle fracture caused by a rapid tearing.

According to the obtained results, it is possible to affirm that the studied failure was caused by two mechanisms. First, a fatigue crack nucleated and then grew steadily in the welded bead, specifically in internal parts of the rail web, where severe stress concentrators were observed (coarse burrs, grinding striations, sharp edges). Second, the fatigue crack grew, initially stably, until a
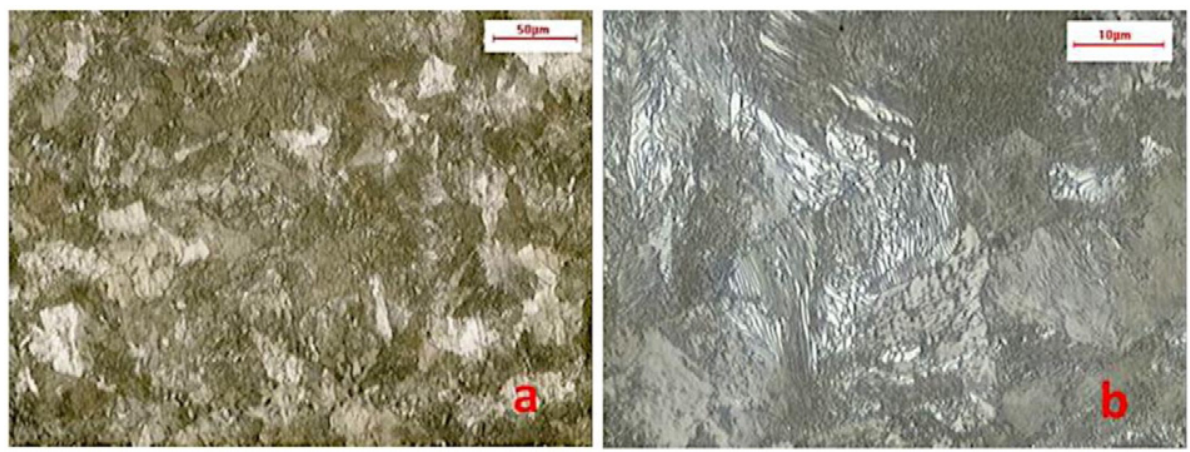

Fig. 4. Micrographs of BM; Nital $2 \%$, OM. (a) $400 \times$; (b) $2000 \times$. 

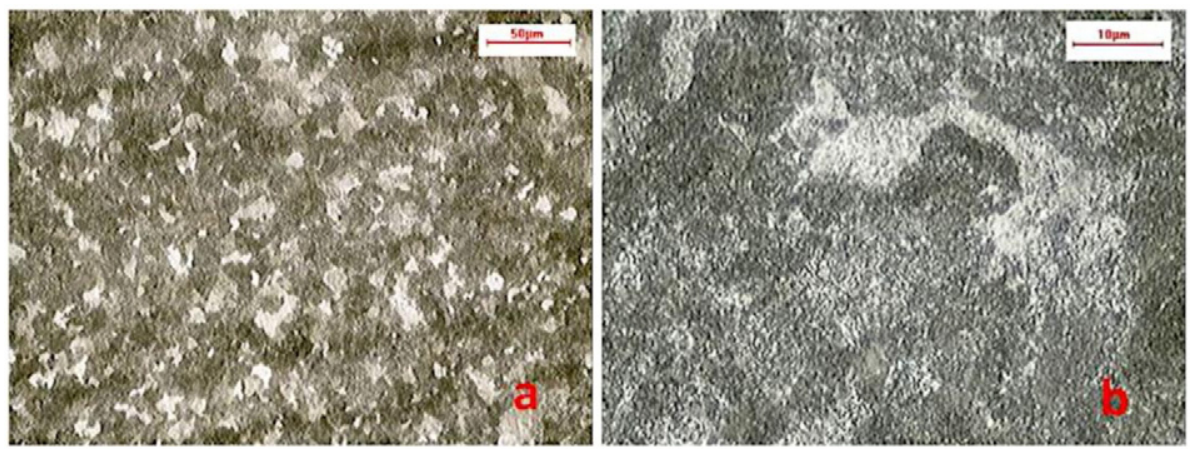

Fig. 5. Micrographs of HAZ; Nital 2\%, OM. (a) 400×; (b) $2000 \times$.
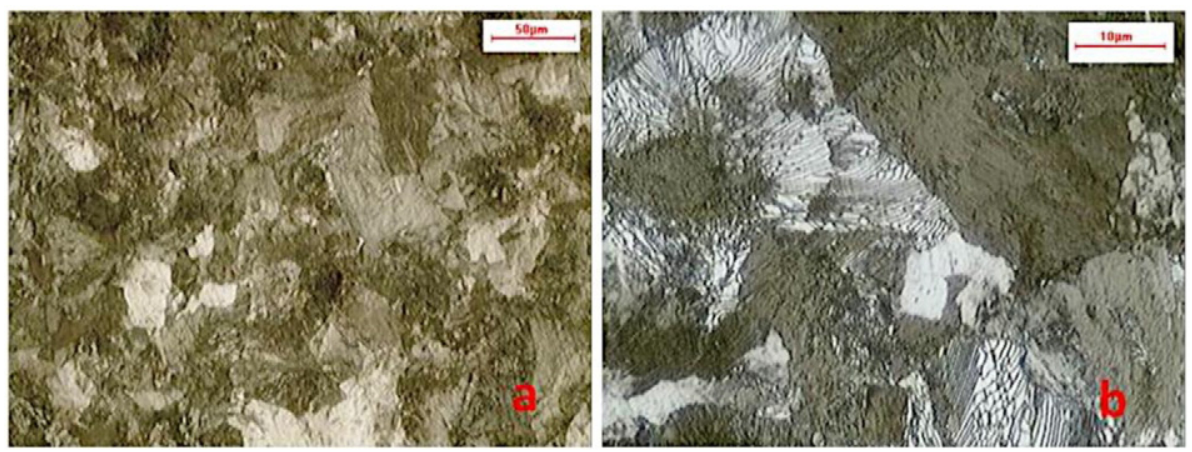

Fig. 6. Micrographs of WB; Nital 2\%, OM. (a) 400×; (b) $2000 \times$.
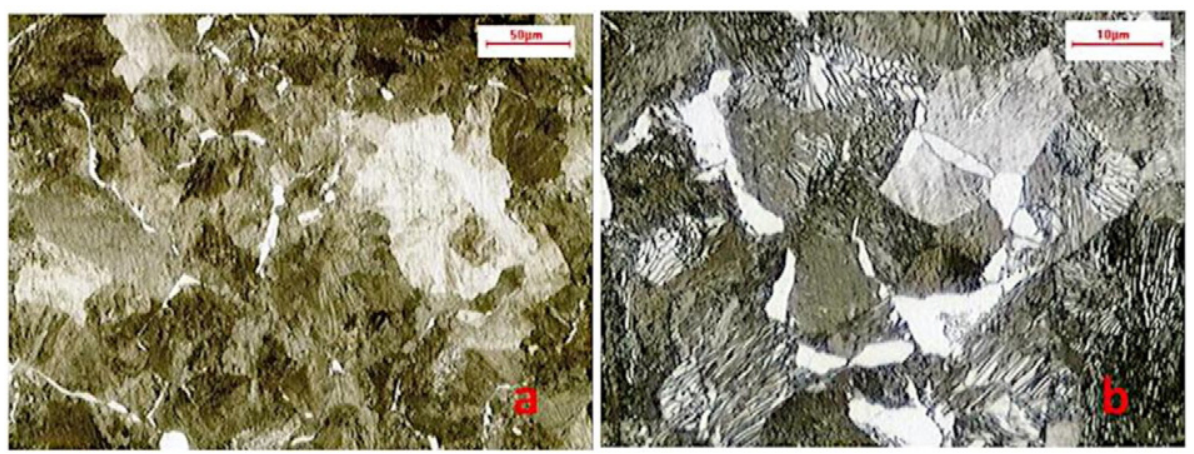

Fig. 7. Micrographs of CL; Nital 2\%, OM. (a) 400×; (b) $2000 \times$.

critical size. As the material studied is a hypereutectoid microalloyed steel, with high mechanical strength and limited ductility, when the crack size was equal to the critical value, the area of the remaining section did not support more cyclic loading and the existing crack grew unstably, until the catastrophic rail fracture.

\subsection{Case 2}

\subsubsection{Macrofractographic analysis}

Fig. 10 presents the start of fatigue cracking from the rail foot, a vertical crack growth through its web and the final fracture in its head. All these steps of fatigue cracking occurred in the welded region.

Fig. 11(a) shows a general view of the fractured surface. It is possible to see two distinct areas: at the rail foot there is a semicircular, dark and flat area (typical of fatigue crack nucleation and stable growth), different from the head and web areas that present chevron marks with high intensity of reflected light (fractured by brittle mechanism).

Fig. 11(b) highlights the foot area, where is possible to observe that the semicircular area has typical characteristics of a nucleation and stable crack growth under fatigue conditions. This area is situated exactly at the weld bead where a coarse burr is 


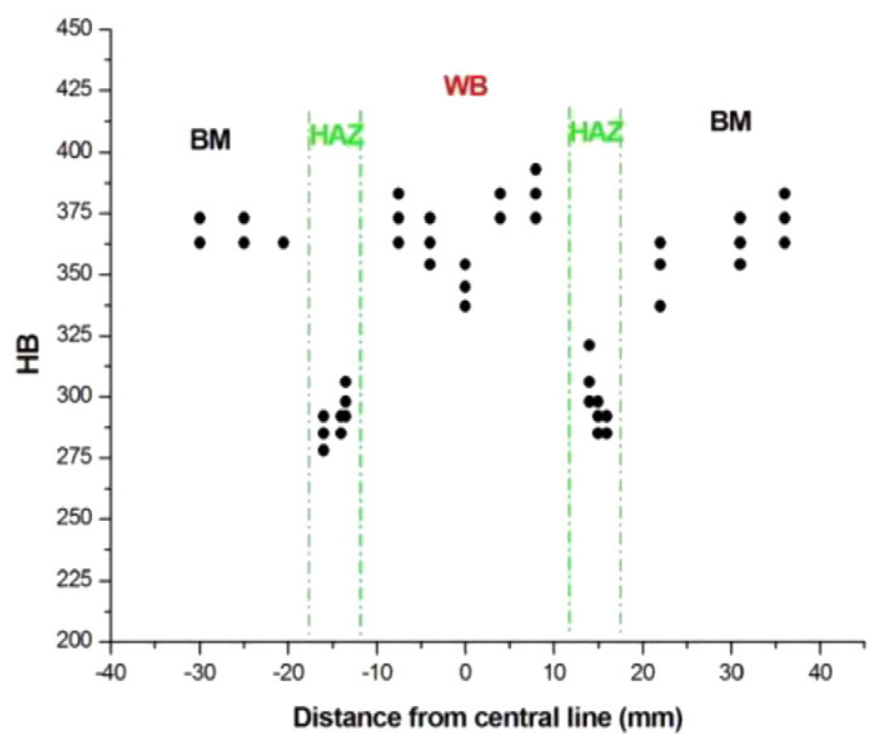

Fig. 8. Brinell hardness data. $\mathrm{BM}=$ base metal; $\mathrm{HAZ}=$ heat affected zone; $\mathrm{WB}=$ weld bead; central line $(\mathrm{CL})$ at reference position 0 .

present (stress concentration). It is supposed that fatigue crack grew until get a specific radius (around $3 \mathrm{~mm}$ ) at the foot of the rail promoting a stress intensity factor correspondent to the material fracture toughness, causing a catastrophic failure at the welded joint.

\subsubsection{Chemical analysis}

This fractured rail was also submitted to a chemical analysis by the optical emission spectrometry technique. The studied material is a hypoeutectoid microalloyed steel. Carbon, chrome and nickel contents are, respectively, $0.600 \%, 0.156 \%$ and $0.148 \%$. This steel presented $0.725 \%, 1.350 \%$ and $0.026 \%$ of $\mathrm{Si}$, Mn and P respectively. The expected microstructure for this steel is mainly constituted by pearlite with a low amount of pro-eutectoid ferrite. The carbon content does not meet the minimum specified values [2].

\subsubsection{Metallographic analysis}

Base metal (BM), heat-affected zone (HAZ) and weld bead (WB) samples were metallographically prepared, etched with Nital $2 \%$ and microstructurally analyzed in an optical microscope (OM). Fig. 12 presents the BM microstructure. It is possible to observe pearlite as the main constituent with a small amount of ferrite. It is noticeable the presence of manganese sulfide inclusions along of all base metal. These inclusions have an elongated morphology aligned with the rail rolling direction.

Fig. 13 presents micrographs of the transition region between the base metal (left) and the HAZ (right). It is observed that this is a region of microstructural discontinuity, where in the base metal there is a structure formed by colonies of well-defined and coarser pearlite, while the HAZ shows a granular aspect, giving evidence of pearlite crumbling (cementite spheroidization), probably due to the high heat input in this area during the welding procedure. These characteristics may be better observed in Fig. 14, which presents micrographs of the HAZ region.

Fig. 15 shows the micrographs of the WB area. It is possible to ensure that pearlite is also the main constituent, however the average size of their colonies is significantly lower, compared to the BM microstructure. Manganese sulfides are also present in WB region with elongated morphology in the rail rolling direction.

A sample from the region where the crack had nucleated under fatigue loading, at the rail foot, was prepared, etched with Nital $2 \%$ and analyzed. Fig. 16 presents the obtained result, where is possible to verify a big amount of pro-eutectoid ferrite between pearlite colonies. This characteristic may be an evidence of local decarburization during welding.

\subsubsection{Microfractographic analysis}

A sample from the rail foot, collected next to the crack nucleation area, was analyzed in a scanning electron microscope (SEM). Fig. 17 presents the microfractographs of two different areas: the fatigue cracks nucleation and crack stable growth regions, as

Table 1

Main tensile test properties.

\begin{tabular}{lclll}
\hline Sample & $\sigma_{\mathrm{ys}}(\mathrm{MPa})$ & $\sigma_{\mathrm{ts}}(\mathrm{MPa})$ & TS $(\%)$ & AR $(\%)$ \\
\hline In welded joint & $977 \pm 18$ & $1155 \pm 1$ & $15 \pm 1$ & $45 \pm 1$ \\
In base metal & $1240 \pm 27$ & $1463 \pm 13$ & $17 \pm 1$ & $34 \pm 5$ \\
\hline
\end{tabular}



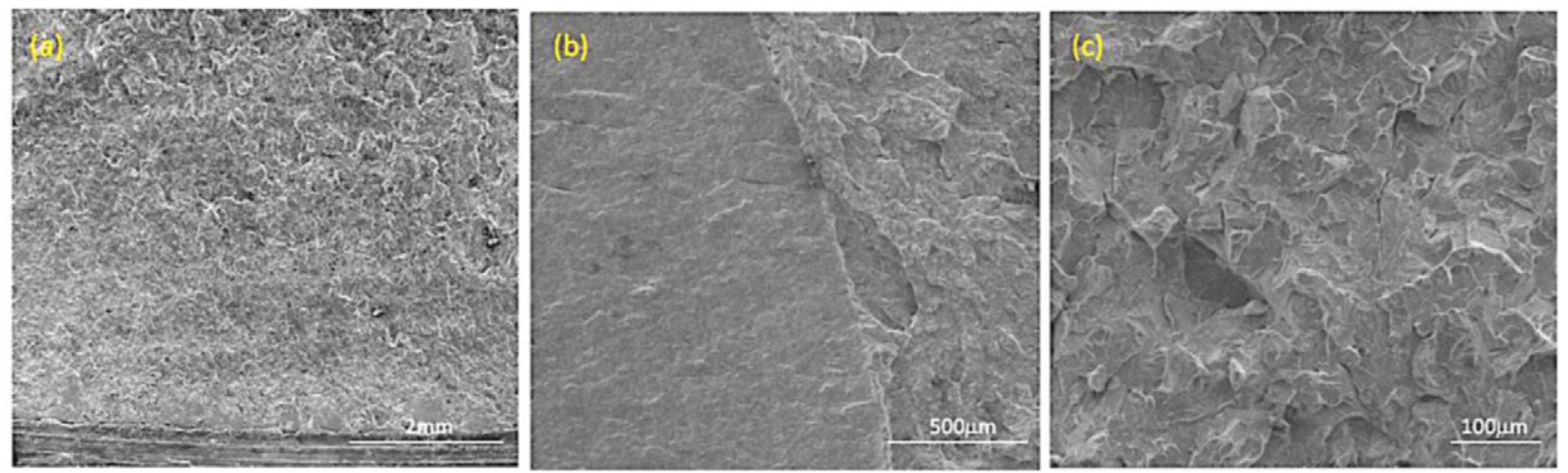

Fig. 9. (a) Start of fatigue crack nucleation and growth; (b) transition area; (c) brittle fracture area. SEM.

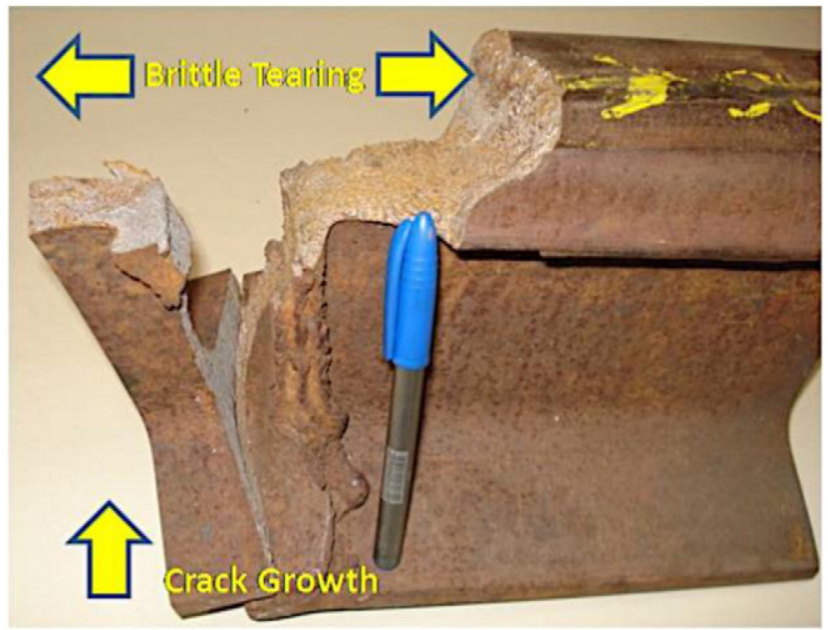

Fig. 10. Crack nucleation and growth from the foot of the rail, resulting in a brittle fracture of the welded bead at web and head areas.

well the unstable tearing area. At the crack stable growth, it is possible to observe a flat surface without plastic deformation, typical of a fatigue crack growth. At the crack unstable growth area there are cleavage facets that are typical characteristics of a brittle fracture.
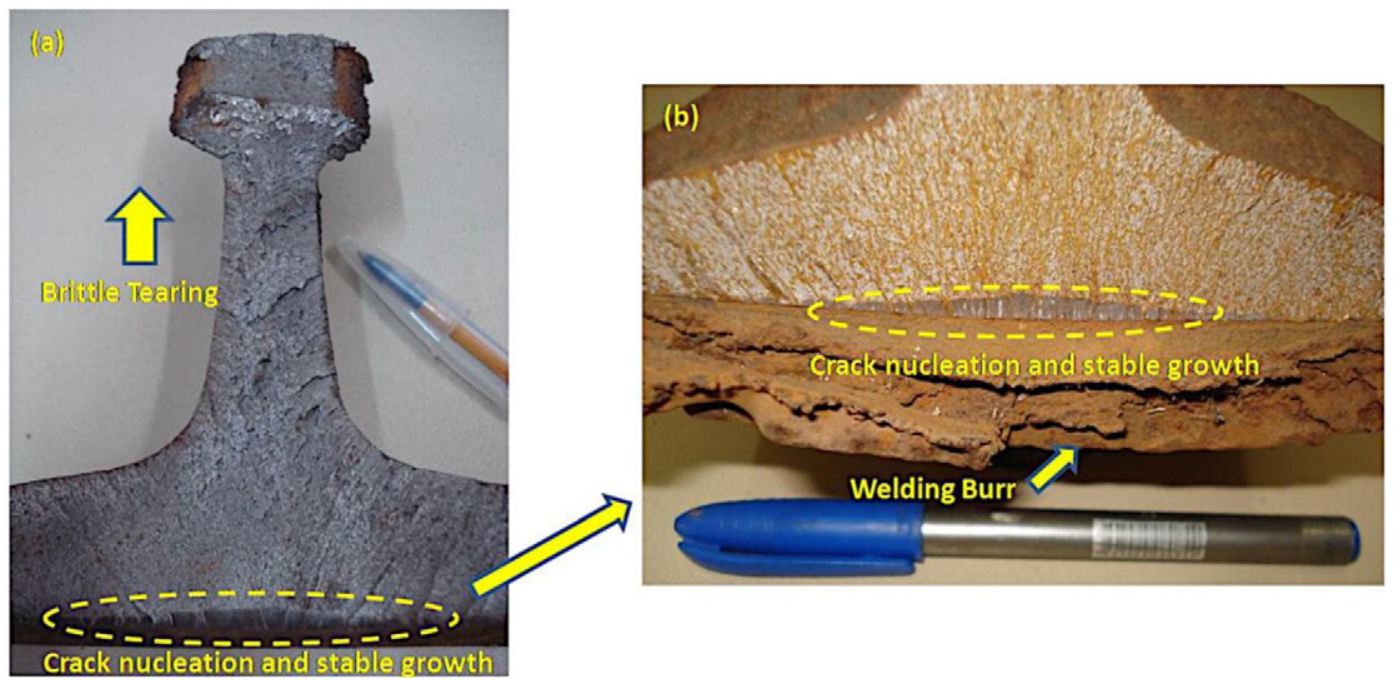

Fig. 11. Fractured surface of the rail in the weld region. (a) General view. (b) Highlighting the foot area where exists a coarse burr. 

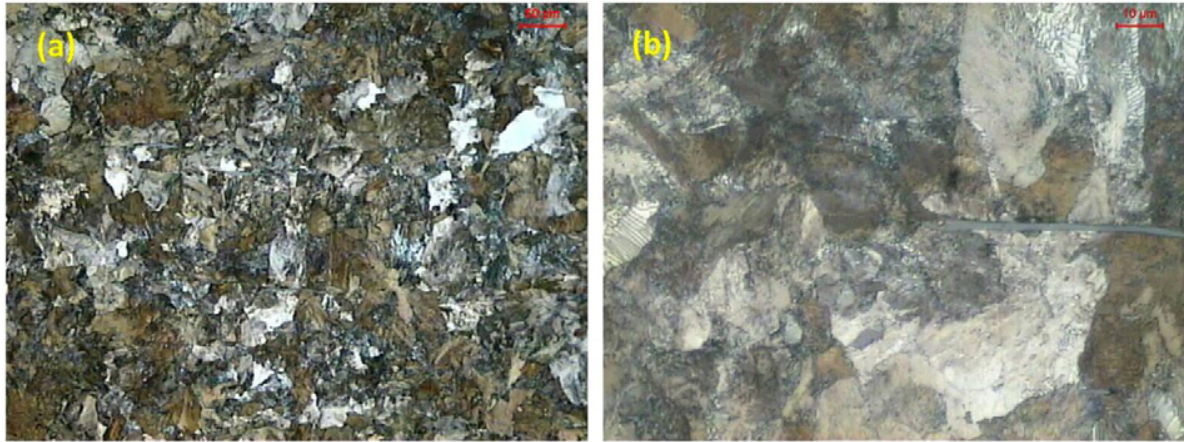

Fig. 12. Micrograph of BM; Nital 2\%, OM. (a) 200×; (b) 1000×.
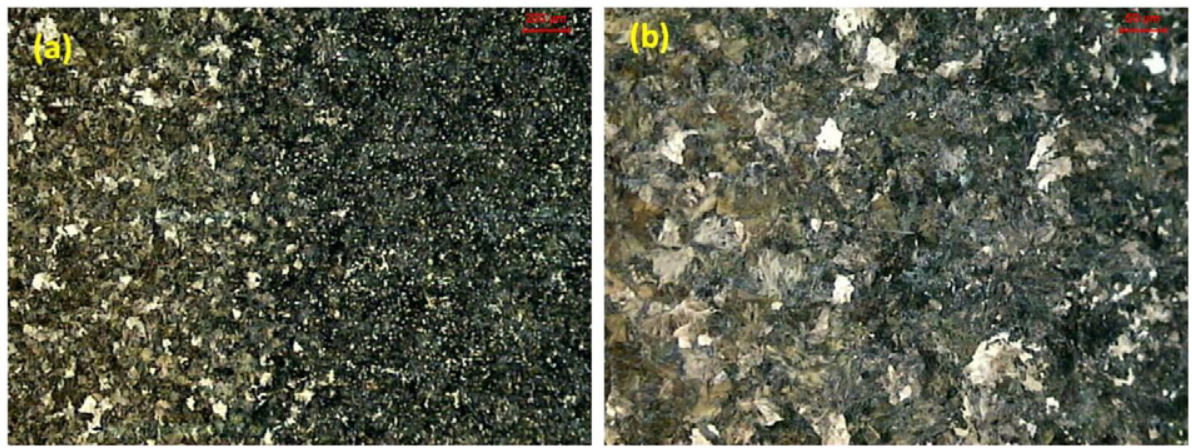

Fig. 13. Micrograph of transition area between BM and HAZ; Nital 2\%, OM. (a) 200×; (b) 1000×.
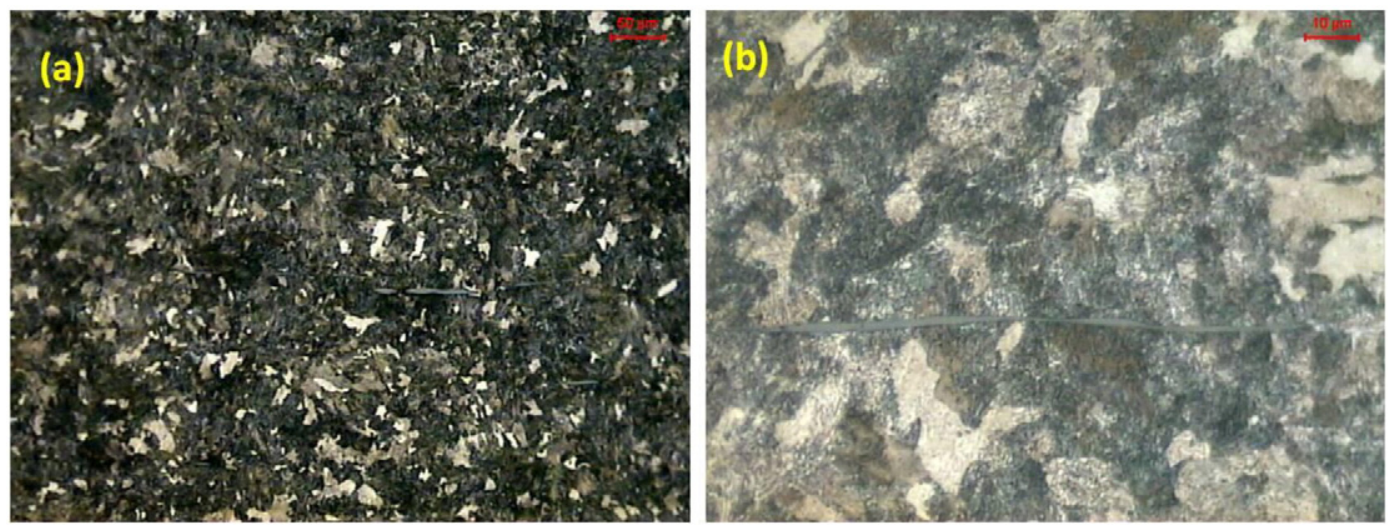

Fig. 14. Micrograph of HAZ; Nital 2\%, OM. (a) 200×; (b) 1000×.
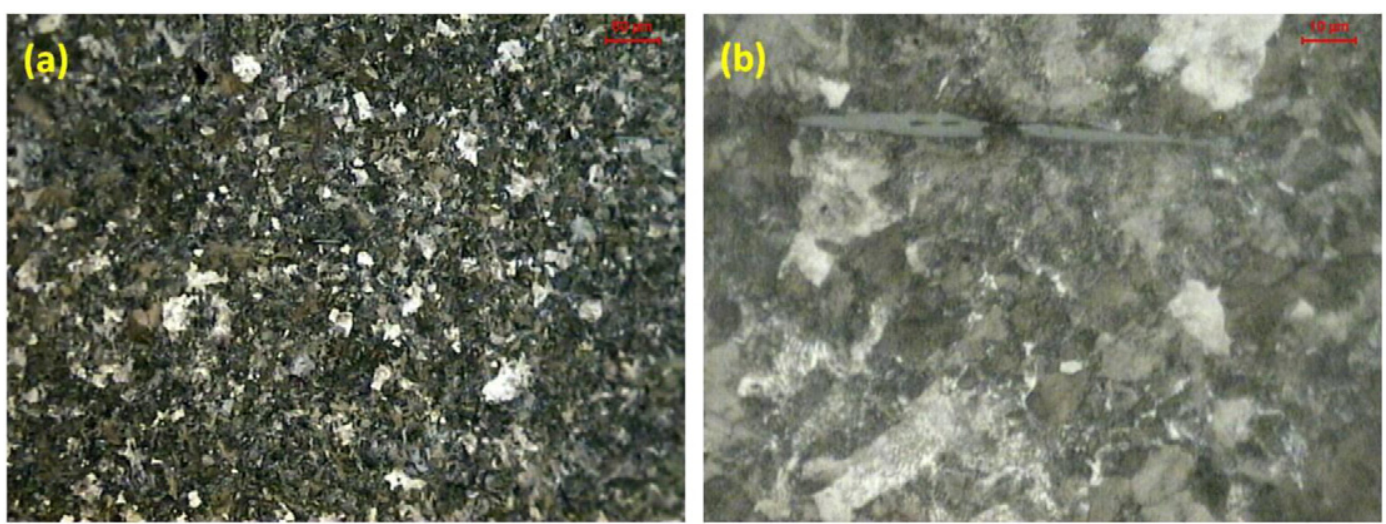

Fig. 15. Micrograph of WB; Nital 2\%, OM. (a) 200×; (b) 1000x. 


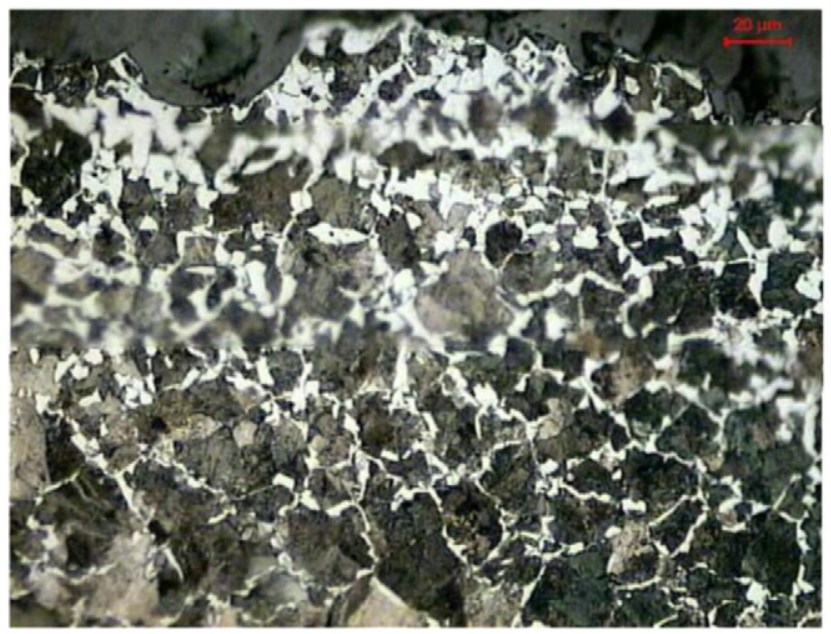

Fig. 16. Micrograph of the crack nucleation area (rail foot); Nital $2 \%$, OM.

According to the obtained results, it is possible to conclude that in this case study, a crack nucleated by fatigue in a rail foot area where already there was a stress concentrator (welding coarse burr) and also a microstructure with big amount of ferrite, and so more susceptible to the fatigue crack nucleation. This crack grew in stable mode until a small critical size (around $3 \mathrm{~mm}$ ) inducing a final brittle tearing.

\section{Conclusions}

Two failures of flash butt-welded rails were investigated, and some conclusions can be drawn:

(1) The nature of working stresses, the characteristics of the welded region (geometry and microstructure) and the aspects of the fracture surfaces suggested that the two welded rails failed by fatigue fracture. There is no other evidence to suggest that the rails failed by other modes.

(2) In Case 1, the fatigue crack nucleated at the rail web, exactly where a grinding rung had been done during the welded joint machining, at the step of burr dimensional control. This stress concentration region was the main root cause of the failure.

(3) In Case 2, the fatigue crack nucleated at the rail foot, where also there was a coarse burr. This stress concentration region was also the main root cause of the failure.

(4) In both cases, a soft microstructure existing in the weld region, with a low resistance to fatigue crack nucleation, contributed with the failure.

(5) In both cases, the fatigue crack grew stably until a relatively small size, leading the rails to a catastrophic brittle tearing.

\section{Recommendations}

Considering the flash butt welding procedure and its consequences on the performance of welded rails, some recommendations are suggested. Before the execution of welding procedures, rail extremities should be well cleaned; undesirable dirt could contaminate the welding line causing the presence of impurities at welded structure. After welding procedures, rails should not

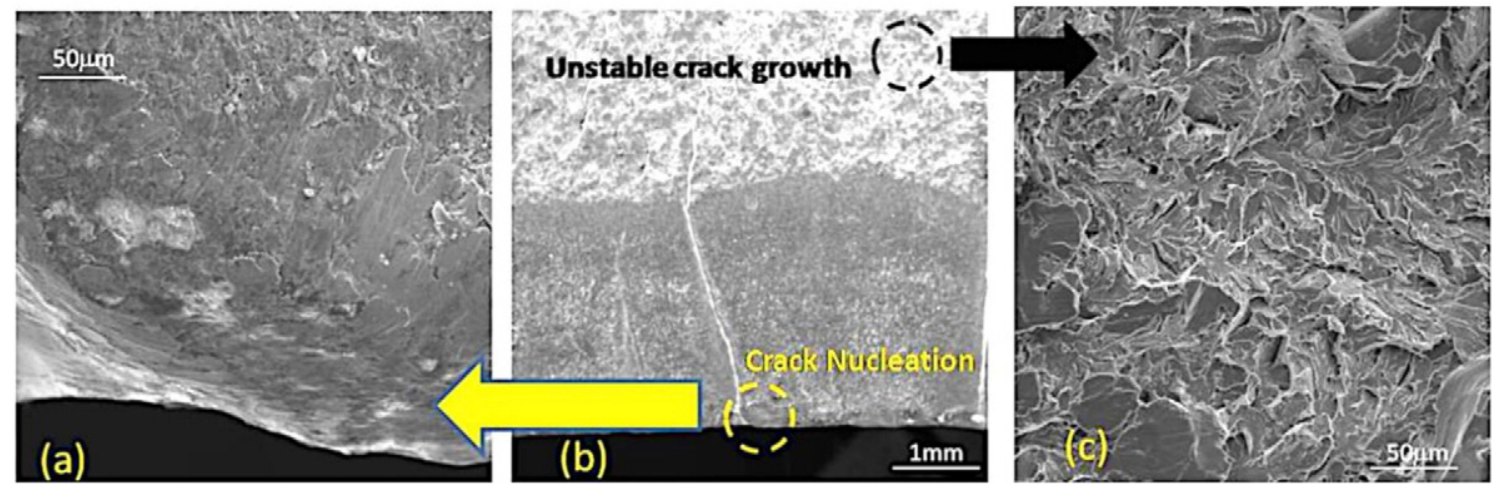

Fig. 17. (a) Start of fatigue crack nucleation and growth; (b) fatigue crack nucleation and growth regions; (c) brittle fracture area. 
be strongly moved while they are in high temperature; rails moving in high temperature may cause permanent strain at welded joint, promoting another structural discontinuity. The dimensional and finishing control of welding burr must be urgently modified; more rigorous criteria for burr removal and superficial finishing must be adopted aiming to diminish the presence of stress concentration points in the welded joint. Welding parameters may be analyzed, to guarantee a minimum microstructure modification at the weld region; a soft microstructure must be avoided, to improve the fatigue crack resistance of the welded joint. Finally, considering the relative small size of the fatigue crack that led to catastrophic failures, it is suggested the use of a steel with chemical composition and microstructure that have higher values of to fatigue crack resistance and also greater fracture toughness.

\section{References}

[1] E.L. Schneider, Análise da Vida Remanescente de Trilhos com Defeitos Transversais Desgastados em Serviço. Dissertação (Mestrado em Engenharia). Programa de Pós-Graduação em Engenharia de Minas, Metalúrgica e Materiais, UFRS, Brazil (2005).

[2] Manual of railway engineering, American Railway Engineering and Maintenance-of-Way Association - AREMA; 2013.

[3] H.A. Aglan, Fatigue crack growth and fracture behavior of bainitic rails steels, Federal Railroad Administration, EUA, 2011.

[4] U. Zerbst, M. Vormwald, C. Andersch, K. Mädler, M. Pfuff, The development of a damage tolerance concept for railway components and its demonstration for railway axle, Eng Fract Mech 72 (2005) 209-239.

[5] U. Zerbst, R. Lundén, K. Edel, R.A. Smith, Introduction to the damage tolerance behaviour of railway rails - a review, Eng Fract Mech 76 (2009) 2563-2601.

[6] U. Zerbst, S. Beretta, Failure and damage tolerance aspects of railway components, Eng Fail Anal 18 (2011) 534-542.

[7] R.C. Rice, Shell and detail fracture formation in railroad rails, in: R.I. Stephens (Ed.), Case studies for fatigue education, ASTM STP 1250 , American Society for Testing and Materials, Philadelphia 1994, pp. 109-138.

[8] A.-M. Hämäläinen, J. Salo, J. Martikainen, Flash welding of nonalloyed welding wire steel, Mechanika 6 (74) (2008) 63-68.

[9] G. Krauss, Steels - Processing, Structure and Performance, ASM, 2005.

[10] H.K.D.H. Bhadeshia, Bainite in steels, Cambridge University Press, 2001.

[11] H. Mansouri, A. Monshi, Microstructure and residual stress variations in weld zone for flash-butt welded railroads, Sci Technol Weld Join 9 (3) (2004) 237-246.

[12] U. Zerbst, M. Schödel, R. Heyder, Damage tolerance investigations on rails, Eng Fract Mech 76 (2009) $2637-2653$.

[13] Y.D. Li, C.B. Liu, X.F. Wu, W.M. Guo, J.B. Shi, A failure study of the railway rail service for heavy cargo trains, Case Stud Eng Fail Anal 1 (2013) $243-248$.

[14] F. Zhang, B. Lv, B. Hu, Y. Li, Flash butt welding steel crossing and carbon steel rail, Mater Sci Eng A 454-455 (2007) $288-292$.

[15] A. Skyttebol, B.L. Josefson, J.W. Ringsberg, Fatigue crack growth in a welded rail under the influence of residual stresses, Eng Fract Mech 72 (2) (2005) 271-285.

[16] D. Tawifik, P.J. Mutton, W.K. Chiu, Experimental and numerical investigations: alleviating tensile residual stresses in flash-butt welds by localised rapid post-weld heat treatment, J Mater Process Technol 196 (s1-3) (2008) 279-291.

[17] P.J. Mutton, E.E. Alvarez, Failure modes in aluminothermic rail welds under high axle load conditions, Eng Fail Anal 11 (2004) $151-166$.

[18] H. Desimone, S. Beretta, Mechanism of mixed mode fatigue crack propagation at rail butt-welds, Int J Fatigue 28 (5-6) (2006) 635-642. 